\title{
Structural and functional evidence for two separate oligosaccharide binding sites of Pasteurella multocida hyaluronan synthase
}

\author{
Floor K. Kooy ${ }^{1,2}$, Hendrik H. Beeftink ${ }^{2^{*}}$, Michel H. M. Eppink ${ }^{2}$, Johannes Tramper $^{2}$, \\ Gerrit Eggink $^{1,2}$, Carmen G. Boeriu ${ }^{1}$ \\ ${ }^{1}$ Food and Biobased Research, Wageningen University and Research Center, Wageningen, The Netherlands \\ ${ }^{2}$ Bioprocess Engineering, Wageningen University and Research Center, Wageningen, The Netherlands; \\ *Corresponding Author: rik.beeftink@wur.nl
}

Received 28 June 2013; revised 12 August 2013; accepted 24 August 2013

Copyright (C) 2013 Floor K. Kooy et al. This is an open access article distributed under the Creative Commons Attribution License, which permits unrestricted use, distribution, and reproduction in any medium, provided the original work is properly cited.

\section{ABSTRACT}

Pasteurella multocida hyaluronan synthase (PmHAS) is a bi-functional glycosyltransferase, containing a $\beta 1,3$-glucuronyltransferase and $\beta 1,4-N$-acetylglucosaminetransferase domain. PmHAS catalyzes the elongation of hyaluronan (HA) through the sequential addition of single monosaccharides to the non-reducing end of the hyaluronan chain. Research is focused on the relation between the length of the HA oligosaccharide and the single-step elongation kinetics from $\mathrm{HA}_{4}$ up to $\mathrm{HA}_{9}$. It was found that the turnover number $k_{\text {cat }}$ increased with length to maximum values of 11 and $14 \mathrm{~s}^{-1}$ for NAc- and UA-transfer, respectively. Interestingly, the specificity constant $k_{\text {cat }} / K_{\mathrm{M}}$ increased with polymer length from $\mathrm{HA}_{5}$ to $\mathrm{HA}_{7}$ to a value of $44 \mathrm{mM}^{-1} \cdot \mathrm{s}^{-1}$, indicating an oligosaccharide binding site with increasing specificity towards a heptasaccharide at the UA domain. The value of $k_{\text {cat }} / K_{\mathrm{M}}$ remained moderately constant around $8 \mathrm{mM}^{-1} \cdot \mathrm{s}^{-1}$ for $\mathrm{HA}_{4}, \mathrm{HA}_{6}$, and $\mathrm{HA}_{8}$, indicating a binding site with significantly lower binding specificity at the NAc domain than at the UA domain. These findings are further corroborated by a structural homology model of PmHAS, revealing two distinct sites for binding of oligosaccharides of different sizes, one in each transferase domain. Structural alignment studies between PmHAS and glycosyltransferases of the GT-A fold showed significant similarity in the binding of the UDP-sugars and the orientation of the acceptor substrate. These similarities in substrate orientation in the active site and in essential amino acid residues involved in substrate binding were utilized to localize the two HA oligosaccharide binding sites.

Keywords: Pasteurella; Hyaluronan; Binding Site; Polymerization; Co-Polymers

\section{INTRODUCTION}

Enzymatic production of glycosaminoglycans has increasingly attracted attention over the last two decades as these polysaccharides are applied multifold in pharmacy and cosmetics. For organ integrity and functioning, glycosaminoglycans are essential since they activate signaling pathways that control cell proliferation, differentiation, adhesion, and migration $[1,2]$. The controlled production of oligosaccharides with a defined chain length and sulfate groups would constitute a breakthrough in medical sciences with potential applications in, for example, anti-cancer therapeutics [3] and disrupting viral invasion and pathogenesis [1]. In nature, glycosaminoglycans are produced by glycosyltransferases that catalyze the transfer of an activated donor sugar to an oligosaccharide acceptor.

One particular glycosaminoglycan is hyaluronan (HA), an alternating copolymer of $\beta 3-N$-acetylglycosamine (GlcNAc) and $\beta 4$-glucuronic acid (GlcUA). Following the initial HA isolation from animal tissues [4-7], it was ascertained that HA was also produced by a small number of microbial pathogens [8-10], employing HA as a cloak in order to disguise themselves from the mammalian immune system. Numerous cultivation procedures have been developed to produce HA utilizing either these pathogenic microorganisms $[8,11,12]$ or safe recombinant hosts [13-18], containing the hyaluronan synthases 
(HAS) that synthesize HA. The quality of the product is crucial since applications of HA depend on the oligo- or polysaccharide length; consequently, the production of HA with defined lengths is required. Innovative production techniques aspire for high molecular weight HA with a moderate length distribution, or polydispersity, by inflicting stress through culture conditions [12,19-21] or by avoiding HA degradation through hyaluronidase [13, $18,21]$.

Recently, it was demonstrated that, for Streptococcus zooepidemicus, overexpression of genes involved in UDP-GlcNAc biosynthesis increased the molecular weight of the HA products [22], indicating that the chain length is controlled by the availability of the substrates. This is corroborated by kinetic data from HAS enzymes of different sources, demonstrating a significantly larger $K_{\mathrm{MNAc}}$ value than $K_{\mathrm{MUA}}$ value [23-26]. Furthermore, the hyaluronan synthase in Pasteurella multocida (PmHAS) possesses the ability to elongate HA oligosaccharides [27], which offers an additional opportunity to optimize product length and polydispersity. The addition of HA oligosaccharides to the reaction in the presence of both UDP-sugars exacerbates the polymerization rate of PmHAS and diminishes the polydispersity of the HA products compared to reactions initiated with only the UDP-sugars [28]. Although these findings have resulted in increased molecular weight products with minimal polydispersity, the kinetic elongation mechanism of HAS enzymes supporting these results remains unknown.

The following is an investigation of single-step elongation kinetics of various HA oligosaccharide chain lengths $\left(\mathrm{HA}_{4}\right.$ up to $\left.\mathrm{HA}_{9}\right)$. Several single-substrate models were evaluated and kinetic parameters were determined for each individual oligosaccharide. Binding affinities for the UA-transferase site were ascertained to be considerably higher than those for the NAc-transferase site and two physically distinct binding sites were indicated and supported by a structural homology model for PmHAS, based on the crystal structure of chondroitin polymerase K4CP [29]. Chondroitin polymerase and PmHAS have a prominent sequence identity and sequence homology ( $62 \%$ and $79 \%$, respectively), resulting in a reliable structural model for PmHAS. With the support of structural alignment studies, similarities in the active sites of PmHAS and other glycosyltransferases have been ascertained such as the location of acceptor binding sites and several conserved amino acids involved in binding the substrates. Conserved regions have been reported before for UDP-sugar binding sites, whereas, in this study, we have also determined structural similarities for the acceptor binding site. To summarize, this study presents evidence for two distinct oligosaccharides binding sites within PmHAS which affects the polydispersity of the HA products.

\section{EXPERIMENTAL}

\subsection{Characterization of PmHAS}

All reagents were purchased from either Fisher or Sigma-Aldrich unless stated otherwise. Purified PmHAS was provided by Merck \& Co. (formerly Organon N.V.). PmHAS represents the soluble PmHAS ${ }^{1-703}$ enzyme, as described by Jing and DeAngelis[30], cloned and expressed in a pET101/D-TOPO expression vector (Invitrogen) with an additional V5 epitope and polyhistidine (6x His) region at the C-terminal end of the enzyme. PmHAS was purified from the crude extract employing affinity chromatography on Ni-NTA columns (Qiagen).

A coupled-enzyme assay, similar to assays created for other glycosyltransferases[23,31,32], was developed to measure PmHAS activity. The coupled-enzyme assay directly links the increase in the UDP by-product of the PmHAS elongation to the decrease of NADH that was spectrophotometrically measured at $340 \mathrm{~nm}$. PmHAS activity was measured varying one of the reaction conditions, while keeping the others constant. The standard reaction buffer incorporated $5 \mathrm{mM} \mathrm{MgCl} 2,112.5 \mathrm{mM}$ $\mathrm{KCl}, 1 \mathrm{M}$ ethylene glycol, and $50 \mathrm{mMTris} \cdot \mathrm{HCl}(\mathrm{pH}$ 8.0) and the assay components $60 \mathrm{U} \mathrm{PK} / \mathrm{ml}, 75 \mathrm{U} \mathrm{LDH} / \mathrm{ml}, 2$ $\mathrm{mM}$ PEP, and $0.4 \mathrm{mM}$ NADH. Bis-Tris $\cdot \mathrm{HCl}$ was used for experiments below $\mathrm{pH} 7$, and Tris· $\mathrm{HCl}$ for the experiments above or at $\mathrm{pH} 7$. The following reaction conditions were varied and measured with the coupled-enzyme assay: $\mathrm{pH} 5.6$ - 9; temperature $20^{\circ} \mathrm{C}-40^{\circ} \mathrm{C} ; 5 \mathrm{mM}$ of either $\mathrm{MgCl}_{2}, \mathrm{MnCl}_{2}, \mathrm{CoCl}_{2}, \mathrm{NiCl}_{2}$, or $\mathrm{CaCl}_{2} ; \mathrm{MgCl}_{2} 5$ - $50 \mathrm{mM}$; viscous buffer either $1 \mathrm{M}$ trehalose, $1 \mathrm{M}$ sucrose, or $0.1-2 \mathrm{M}$ ethylene glycol. Concentrations of PmHAS, sugar nucleotides, and $\mathrm{HA}_{4}$ were kept constant at $50 \mu \mathrm{g} / \mathrm{ml}, 5.5 \mathrm{mM}$ and $0.1 \mathrm{mM}$, respectively. In experiment with varying $\mathrm{MgCl}_{2}$ concentrations, substrate concentrations were $1 \mathrm{mM}$ for both UDP-sugars and $0.1 \mathrm{mM}$ for $\mathrm{HA}_{4}$.

The reactions were measured at $35^{\circ} \mathrm{C}$ for $20 \mathrm{~min}$ in 96-well150 $\mu \mathrm{l}$ UV star microplates (Greiner Bio-One, Germany) and a temperature-controlled Safire spectrophotometer (Tecan, Switzerland). Following measurement of the absorbance reduction, reactions were discontinued by $15 \mathrm{~min}$ of heating at $95^{\circ} \mathrm{C}$ and then placed in the freezer $\left(-20^{\circ} \mathrm{C}\right)$ until analysis through gel electrophoresis. PmHAS activity was also examined for 1 and 5 hours of reaction at $\mathrm{KCl}$ concentrations ranging from 0 to $200 \mathrm{mM}$; because $\mathrm{KCl}$ is needed for PK activity, this experiment was only analyzed through gel electrophoresis.

\subsection{HA Product Analysis by Gel Electrophoresis}

Reaction mixtures were analyzed on $20 \%$ TBE polyacrylamide gels (Invitrogen) by gel electrophoresis and 
stained by Stains-All [33]. On the gels, Generuler DNA ladder Ultra low range (Invitrogen) was employed as a marker.

\subsection{PmHAS Activity in Single-Step Elongations}

Initial rates were evaluated at $35^{\circ} \mathrm{C}$ for each one-step elongation from $\mathrm{HA}_{4}$ up to $\mathrm{HA}_{9}$ with the coupled-enzyme assay with $60 \mathrm{u} \mathrm{PK} / \mathrm{ml}, 75 \mathrm{u} \mathrm{LDH} / \mathrm{ml}, 2 \mathrm{mM}$ phosphoenolpyruvate, $0.4 \mathrm{mM} \mathrm{NADH}, 15 \mathrm{mM} \mathrm{MgCl}_{2}$, $112.5 \mathrm{mM} \mathrm{KCl}, 1 \mathrm{M}$ ethylene glycol, $50 \mathrm{mMTris} \cdot \mathrm{HCl}$ at $\mathrm{pH}$ 8.0. Reaction mixtures contained a single purified HA oligomer (obtained from Hyalose, L.L.C, USA) and one tyoe of monomer. Single-step elongations of evennumbered oligosaccharides as a substrateproceeded at saturating UDP-GlcNAc concentrations of $40 \mathrm{mM}$ in the absence of UDP-GlcUA, while elongationsof odd-numbered oligomers were performed at saturating UDPGlcUA concentrations of $1 \mathrm{mM}$ in the absence of UDPGlcNAc. This setup ascertained reactions to be single-step elongations. After $5 \mathrm{~min}$ of incubation, the reaction was initiated by addition of $5 \mu \mathrm{g} / \mathrm{ml}$ PmHAS and various oligosaccharide concentrations $(0.1,0.5,1,2,4$, or $6 \mathrm{mM}$ ). Reactions were discontinued by $15 \mathrm{~min}$ heating at $95^{\circ} \mathrm{C}$; enzymes were then removed with a Microcon YM-30 centrifugal filter unit (Millipore). Samples were desalted with Dowex AG 50W-X8 (Bio-rad Laboratories) before measuring product formation by Matrix Assisted Laser Desorption/Ionization Time of Flight Mass Spectrometry (MALDI-TOF MS).

For the MALDI-TOF MS analysis, an Ultraflex workstation (BrukerDaltonics, Germany) with a $337 \mathrm{~nm}$ laser was employed. The mass spectrometer was operated in positive mode and calibrated with a mixture of maltodextrins (mass range 250 - $2500 \mathrm{Da}$ ). The laser irradiance was adjusted between $29 \%$ and $32 \%$ of the full laser power and, following a delayed extraction period of 200 ns. Ions were accelerated by a $25 \mathrm{kV}$ voltage and detected in the reflector mode. For data collection, 200 shots were used. Samples were diluted 10 times in a matrix solution prepared with solution of $10 \mathrm{mg}$ of 2,5-dihydroxybenzoic acid (DHB) in water. ; for analysis, $2 \mathrm{ml}$ of the mixture was transferred to a MALDI sample plate and dried under a stream of warm air.

\subsection{Analysis of Kinetic Data}

Three one-substrate equations were matched to the kinetic datato find the best fit. The Michaelis Menten, Hill, and substrate inhibition equations [34,35] were fitted in Excel with unweighted nonlinear regression:

$$
v=\frac{v_{\max } \cdot H A}{K_{M}+H A} \quad \begin{gathered}
\text { Michaelis } \\
\text { Menten }
\end{gathered}
$$

$$
\begin{array}{ll}
v=\frac{v_{\max } \cdot H A^{n}}{K_{\mathrm{M}}^{n}+H A^{n}} & \text { Hill } \\
v=\frac{v_{\max } \cdot H A}{K_{\mathrm{M}}+H A+H A^{2} / K_{\mathrm{i}}} & \text { substrate } \\
\text { inhibition }
\end{array}
$$

with $v$ indicating the reaction rate by volume, $v_{\max }$ its (virtual) maximum and equal to $k_{\mathrm{cat}} E, k_{\mathrm{cat}}$ the turnover number, $E$ the enzyme concentration, $H A$ the oligosaccharide concentration, $K_{\mathrm{M}}$ the saturation constant, $K_{\mathrm{I}}$ the inhibition constant. The uncertainties of the fits, standard deviations of the parameters and the correlation matrices were determined with the Excel SolverAid macro [36]. Goodness of fit for the three models was evaluated from graphical plots, such as residual and normal probability plots, and by analysis of the following goodness-of-fit estimators: stability of the model; the corrected Akaike criterion; $S_{y . x}$; the correlation between the estimated parameters $k_{\text {cat }}, K_{\mathrm{M}}, n$ or $\mathrm{K}_{\mathrm{i}}$; and the standard deviation of these estimates [37,38].

\subsection{Competition Studies}

Competition at the oligosaccharide site was evaluated by measuring the activity of, for example, the elongation of an even-numbered oligosaccharide by UDP-GIcNAc as a sugar donor in the presence of an odd-numbered HA that cannot be extended by this donor sugar [39]. Activity was measured by the coupled-enzyme assay under identical reaction conditions as used for kinetic studies but also containing $10 \mathrm{mM}$ UDP-GlcUA or $20 \mathrm{mM}$ UDPGlcNAc. Reactions of $\mathrm{HA}_{4}, \mathrm{HA}_{5}$ and $\mathrm{HA}_{6}$ were individually monitored in the presence of a competing oligosaccharide with a molar ratio between the reacting and competing oligosaccharides of 1:1 or 1:10. Reactions of $0.3 \mathrm{mM}$ reacting oligosaccharide with the omission of the competing oligosaccharide were taken as a reference.

\subsection{Structure Homology Modeling}

Model building and energy minimization of PmHAS was performed with Modeler using the Accelrys Discovery Studio 2.1 software package with $\mathrm{K} 4 \mathrm{CP}$ as a template structure. The protein model was validated with Profiles-3D (Accelrys Discovery Studio 2.1), the stereochemical quality of the homology model was verified by PROCHECK [40], and the protein folding was assessed with PROSAII [41]. Docking studies of HA oligosaccharides were performed with the program AutodockVina [42]. Structural alignment was performed utilizing DaliLite [43]. Structural alignment of enzymes was evaluated by their root mean square deviation (RSMD) and Zscores. Low RSMD values (below $4.0 \AA$ ) and elevated Z-scores (above 2) are an indication of a favorable structural superimposition and may indicate a conserved 
fold structure. All structural images were generated with PyMOL version 0.99 (Delano Scientific LLC, San Carlos, California, USA).

\subsection{Polymerization Reactions with $\mathrm{HA}_{4}$-Fluor}

Purified $\mathrm{HA}_{4}$ oligosaccharides were labeled with the fluorophoreanthranillic acid at the reducing end of the chain. Labeling and purification of $\mathrm{HA}_{4}$-fluor was accomplished as described before [33]. All reactions contained $2 \mathrm{mM}$ UDP-GlcUA, $40 \mathrm{mM}$ UDP-GlcNAc, 15 $\mathrm{mM} \mathrm{MgCl} 2,1 \mathrm{M}$ ethylene glycol, and $50 \mathrm{mMTris} \cdot \mathrm{HCl}$ at $\mathrm{pH}$ 8.0. The $\mathrm{HA}_{4}$-fluor concentration was maintained at saturating values $(2.5 \mathrm{mM})$ or at subsaturating values $(0.1 \mathrm{mM})$. Reactions were initiated by adding either 15 or $30 \mu \mathrm{g} / \mathrm{ml}$ PmHAS and performed in $7.5 \mu \mathrm{l}$ of reaction volume in PCR eppendorf tubes. The reaction progress was analyzed for $130 \mathrm{~min}$ at $30^{\circ} \mathrm{C}$; every 5 or $10 \mathrm{~min}$, the reaction of 1 sample tube was discontinued by freezing in liquid nitrogen and maintaining it at $-20^{\circ} \mathrm{C}$. Following the experiments, all samples were heated for $15 \mathrm{~min}$ at $95^{\circ} \mathrm{C}$ and analyzed on $20 \%$ TBE polyacrylamide gels; gel images were processed as described elsewhere [33].

\section{RESULTS AND DISCUSSION}

\subsection{Kinetic Characteristics}

A combination of kinetic characterization and structural modeling was employed in order to study the polymerization of hyaluronan by Pasteurella multocida hyaluronan synthase (PmHAS), focusing on the influence of the oligosaccharide length on the turnover number $\left(k_{\text {cat }}\right)$ and the specificity constant $\left(k_{\text {cat }} / K_{\mathrm{M}}\right)$. Kinetic results are first introduced that characterize the optimal conditions for PmHAS activity. To accomplish this, single-step elongation kinetics were investigated, including the influence of competing oligosaccharides on the polymerization rate. Subsequently, a structural homology model of PmHAS is considered, and structural relations to other glycosyltransferases are then submitted. Utilizing the determined kinetic parameters, we demonstrate that - due to two oligosaccharide binding sites - product polydispersity increases at sub-saturating HA concentrations.

\subsubsection{Characterization of PmHAS}

The polymerization activity of PmHAS was measured to study optimal conditions for elongation with $\mathrm{HA}_{4}$ as template and equimolar amounts of both UDP sugar substrates. The reaction conditions that were varied included: $\mathrm{pH}$, temperature, the nature of the divalent ions and the stabilizing buffer components. PmHAS activity has a $\mathrm{pH}$ optimum between 7.5 and 9 (Figure 1(A)), with highest activity at $\mathrm{pH} 8$. Activity increased with increasing temperature (Figure $1(B)$ ) to $35^{\circ} \mathrm{C}$, after which activity decreases, probably due to enzyme inactivation. At optimal $\mathrm{pH}$ and temperature, elevated molecular weight products were obtained with a narrow product range (Figures 1(A) and (B)). The nature of the divalent metal ions signifycantly affected the PmHAS activity; most efficient was $\mathrm{Mg}^{2+}$, whereas the activity decreased to $70 \%$ with $\mathrm{Mn}^{2+}$ or $\mathrm{Co}^{2+}$, to $28 \%$ for $\mathrm{Ni}^{2+}$ and to $22 \%$ for $\mathrm{Ca}^{2+}$ (Figure 1(C)). PmHAS activity was optimal at $15 \mathrm{mM}$ of $\mathrm{MgCl}_{2}$. Bufferviscogens, such as ethylene glycol or trehalose, not only influenced PmHAS activity, but also affected product polydispersity (Figure 1(D)). Significantly lower polydispersity and a high activity were found at $1 \mathrm{M}$ of ethylene glycol. Varying the ethylene glycol concentration from 0.1 up to $2 \mathrm{M}$ resulted in minor changes in PmHAS activity; activity was highest at $1 \mathrm{M}$ ethylene glycol (not shown). The following conditions were therefore selected for kinetic experiments: $\mathrm{pH} 8.0,35^{\circ} \mathrm{C}$, $15 \mathrm{mM} \mathrm{Mg}^{2+}$ and $1 \mathrm{M}$ ethylene glycol.

PmHAS activity in cell membrane preparations has been previously described with a maximum between pH 6.8 and 7.6 and a $2-3$ fold higher activity withMn ${ }^{2+}$ than with $\mathrm{Mg}^{2+}$ [44]. Differences in optimal conditions are possibly a result of the use of isolated PmHAS in our studies. Similar $\mathrm{pH}$ and temperature optima were reported for hyaluronan synthases from Streptococcus equisimilis (SeHAS) and Xenopuslaevis (XIHAS) [24, 45]. The metal ion preference of PmHAS is also comparable with that observed for XlHAS. The most effective divalent metal ion for XIHAS was $\mathrm{Mg}^{2+}$ with a 4- to 10-fold reduction with $\mathrm{Mn}^{2+}, \mathrm{Ni}^{2+}$ or $\mathrm{Co}^{2+}$ [24]. Although the metal ion preference was not reported for other HAS enzymes, the corresponding activity assays included $15-20 \mathrm{mM}$ of $\mathrm{MgCl}_{2}$ [25,26,46,47], suggesting that $\mathrm{Mg}^{2+}$ is the preferred ion for HAS enzymes in general. In addition, viscous compounds increased SeHAS activity as well as PmHAS activity when employing ethylene glycol and sucrose below $0.5 \mathrm{M}$; however, when increasing the concentration of these viscogens, SeHAS activity exhibited inhibition [45].

\subsubsection{Influence of Oligosaccharide Length on $\boldsymbol{k}_{\mathrm{cat}}$ and $\boldsymbol{K}_{\mathrm{M}}$}

$\mathrm{HA}_{n}$ oligosaccharides, (with $n$ ranging from 4 to 9), were individually elongated in single-step reactions with the corresponding sugar nucleotide in excess (UDPGlcNAc for even-numbered and UDP-GlcUA for oddnumbered oligosaccharides). The non-reducing end, where elongation occurs, contains a GlcUA sugar for the even-numbered oligosaccharides, and, mutatis mutandis, a GlcNAc sugar for the odd-numbered oligosaccharides. The reaction progress was analyzed employing the coupled enzyme assay described in the Experimental section. 

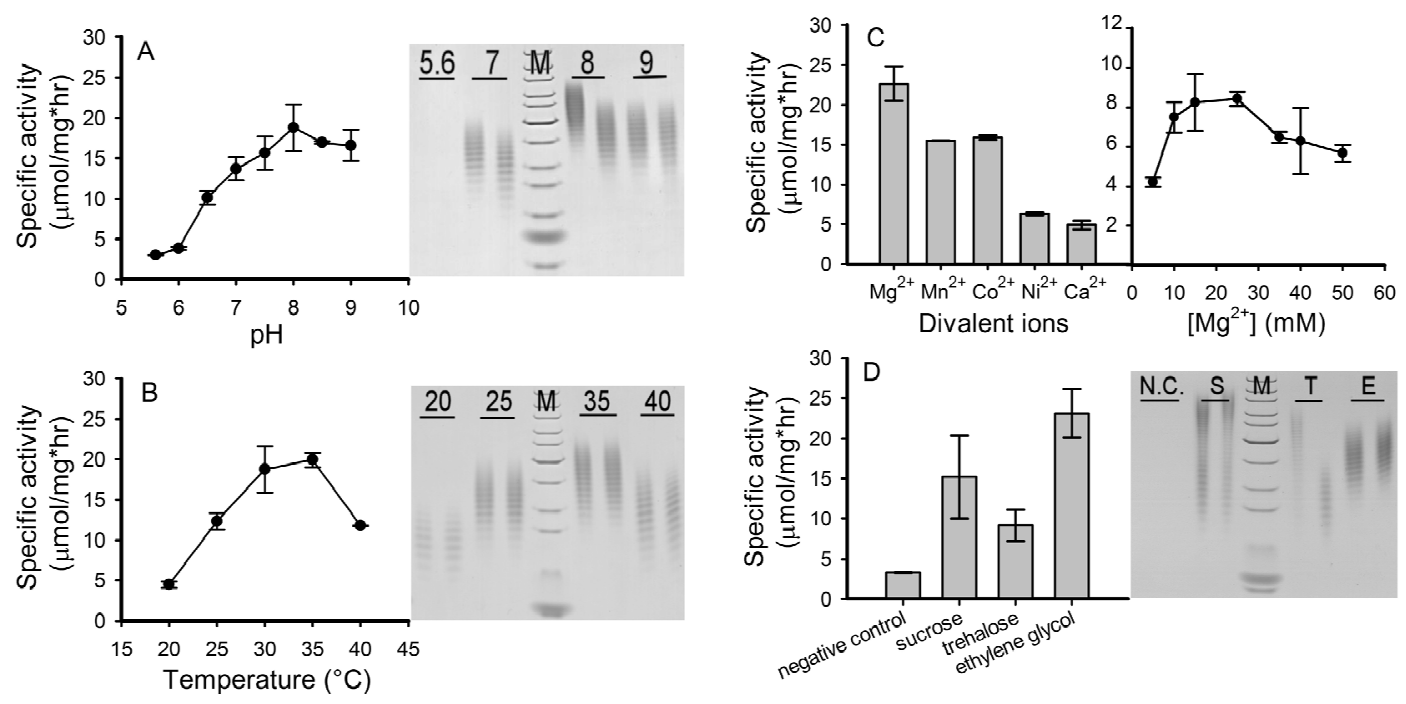

Figure 1. Specific activity of PmHAS under different reaction conditions. (A) pH dependency of PmHAS activity; reaction products at $\mathrm{pH}$ 5.6, 7, 8 and 9 were analyzed on gel; most abundant and longest products were observed at p H8. M indicates the Generuler DNA ladder; bars demonstrate the corresponding duplicates. (B) Temperature dependency of PmHAS activity; reactions products at $20^{\circ} \mathrm{C}, 25^{\circ} \mathrm{C}, 35^{\circ} \mathrm{C}$ and $40^{\circ} \mathrm{C}$ were analyzed on gel. Product size and amount concur with activity measurements; (C) Effect of divalent ions on PmHAS activity. Best results were obtained with $15 \mathrm{mM} \mathrm{Mg}^{2+}$. (D) Effect of viscogens on PmHAS activity; sucrose (S), trehalose (T) and ethylene glycol (E) were compared to a viscogen-less buffer as negative control (N.C.). Gel analysis of reaction products show ethylene glycol to stimulate low polydispersity.

MALDITOF-MS confirmed the formation of the expected products $\mathrm{HA}_{(\mathrm{n}+1)}$ in all reactions (data not shown). Since the corresponding UDP-sugar is in excess, the elongation can be considered as a one-substrate reaction [34]. Three models for one substrate kinetics were used for fitting the data by nonlinear regression: the Michaelis-Menten equation, the substrate-inhibition equation and the Hill equation (see the Experimental section). These models were selected to determine if PmHAS elongates HA through classical Michaelis kinetics or if the elongation was regulated by other mechanisms, such as cooperativity or substrate inhibition.

Goodness-of-fit was judged statistically by examination of residual and normal probability plots, by evaluation of standard deviations of the estimated parameters $k_{\text {cat }}$ and $K_{\mathrm{M}}$, and by statistical tests such as the corrected Akaike criterion. These statistical tests demonstrated that all three models fitted well (Table 1). However, the Hill equation was found to reduce to the Michaelis Menten equation, since the estimated Hill number $n$ equaled unity for every reaction. In addition, the substrate inhibition model did not allow accurate estimation of $k_{\text {cat }}$ and $K_{\mathrm{M}}$. The substrate inhibition model resulted in substantial standard deviations for these parameters, and a very strong correlation between $k_{\text {cat }}$ and $K_{\mathrm{M}}$ varying from 0.90 to 0.99 , which was not observed for the other models. In summary, the Michaelis Menten equation was superior for the present concentration range, although substrate inhibition may possibly become relevant at elevated oli- gosaccharide concentrations.

Experimental data and their Michaelis Menten fit are depicted in Figure 2; the resulting values for $k_{\text {cat }}$ and $K_{\mathrm{M}}$ are given in Table 2. To the best of our knowledge, it is the first time that these kinetic parameters are reported for individual oligosaccharides for any of the HAS enzymes. Globally, the value of the turnover number $k_{\text {cat }}$ is seen to increase with oligosaccharide length; this increase levels off at higher lengths. In addition, evennumbered HA polymers seem to feature a lower $k_{\text {cat }}$ than the next larger odd-numbered ones. Figure 3 illustrates this behavior and shows a general increase with length as well as (considering the relatively small standard deviations) the difference in $k_{\text {cat }}$ values between odd-numbered and even-numbered oligosaccharides. Since no literature values for $k_{\text {cat }}$ are available as a reference, we use specific activity values for comparison. The UA-transferase specific activity of approximately $450 \mu \mathrm{mol} / \mathrm{mg} \cdot \mathrm{hr}$ observed for $1 \mathrm{mM} \mathrm{HA}_{7}$ or $\mathrm{HA}_{9}$ at $1 \mathrm{mM}$ UDP-GlcUA (Figure 2) are virtually equal to the reported value of $484 \mu \mathrm{mol} / \mathrm{mg} \cdot \mathrm{hr}$ for HA21 [39]. This indicates that the maximal rate at the UA-transferase domain is attained utilizing a heptasaccharide or longer. The NAc-transferase specific activities with values of $175 \mu \mathrm{mol} / \mathrm{mg} \cdot \mathrm{hr}$ observed in our study for $1 \mathrm{mM} \mathrm{HA}_{8}$ at $1 \mathrm{mM}$ UDP-GlcNAc is seven times higher than reported [39]. Maximal NAc-transferase rates were only reached in our studies at elevated UDP-GlcNAc concentration of 40 $\mathrm{mM}$; which is considerably higher than the value of 


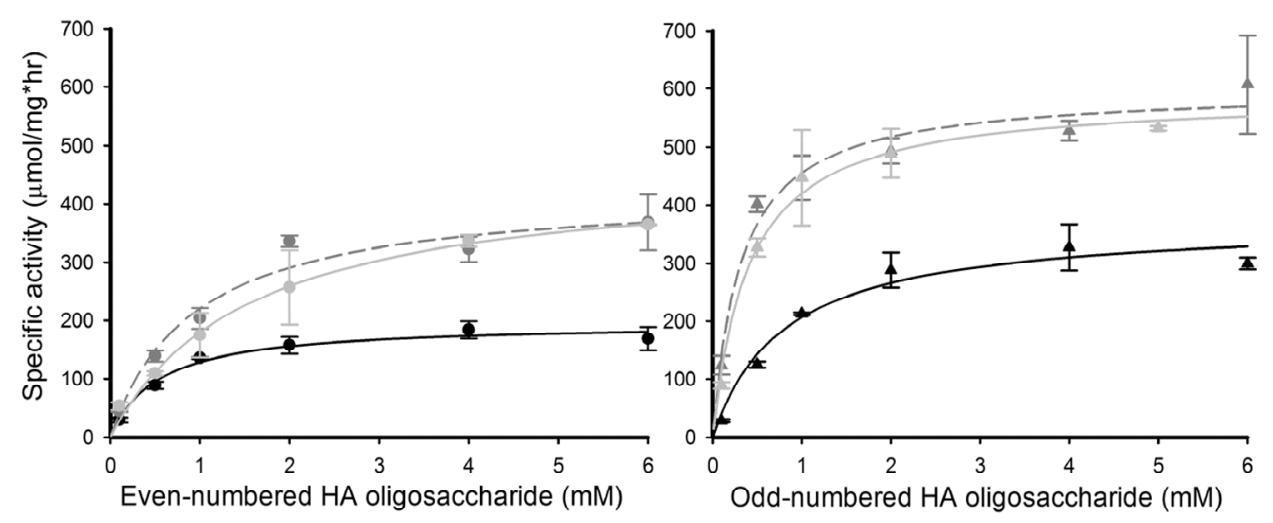

Figure 2. Effect of HA concentration and length on the specific activity of PmHAs. Elongation rates for three even-numbered oligosaccharides, HA4 $(\bullet)$, HA6 $(\bullet)$, and HA8 $(\bullet)$, and three odd-numbered oligosaccharides, HA5 $(\boldsymbol{\Delta})$, HA7 $(\boldsymbol{\Delta})$, and HA9 $(\boldsymbol{\Delta})$, were measured at varying oligosaccharide concentrations from 0.1 to $6 \mathrm{mM}$ and the corresponding UDP-sugar in excess. The lines, solid ones for HA4, HA8, HA5 and HA9 and dashed ones for HA6 and HA7, are Michaelis Menten fits.

Table 1. Model selection on basis of goodness of fit for three kinetic models: 1MichaelisMenten, Eq.1; 2 Hill, Eq.2; 3 substrate inhibition, Eq.3 for single-step elongation of HA by PmHAS.

\begin{tabular}{|c|c|c|c|c|c|c|}
\hline substrate & eq. & $S S_{\mathrm{r}}$ & $A I C \mathrm{c}$ & $D_{\mathrm{AICc}}$ & $\begin{array}{l}\text { Parameter } \\
\text { correlation }\end{array}$ & $S_{y x}$ \\
\hline \multirow[t]{4}{*}{$\mathrm{HA}_{4}$} & 1 & 1607 & 67.8 & 0.0 & 0.81 & 12.7 \\
\hline & 2 & 1469 & 71.4 & 3.6 & $0.41-0.77$ & 12.8 \\
\hline & 3 & 1186 & 68.8 & 1.0 & $0.91-0.97$ & 11.5 \\
\hline & 1 & 9228 & 88.7 & 0.0 & 0.86 & 30.4 \\
\hline \multirow[t]{3}{*}{$\mathrm{HA}_{6}$} & 2 & 8713 & 92.8 & 4.1 & $0.66-0.88$ & 31.1 \\
\hline & 3 & 8369 & 92.3 & 3.6 & $0.94-0.98$ & 30.5 \\
\hline & 1 & 7511 & 85.7 & 0.0 & 0.91 & 26.7 \\
\hline \multirow[t]{3}{*}{$\mathrm{HA}_{8}$} & 2 & 6590 & 89.4 & 3.7 & $0.94-0.99$ & 27.1 \\
\hline & 3 & 7151 & 90.4 & 4.7 & $0.92-0.97$ & 28.2 \\
\hline & 1 & 6956 & 85.3 & 6.3 & 0.85 & 26.4 \\
\hline \multirow[t]{3}{*}{$\mathrm{HA}_{5}$} & 2 & 4429 & 84.6 & 5.6 & $0.34-0.74$ & 22.2 \\
\hline & 3 & 2777 & 79.0 & 0.0 & $0.97-0.99$ & 17.6 \\
\hline & 1 & 18732 & 97.2 & 0.0 & 0.76 & 43.3 \\
\hline \multirow[t]{3}{*}{$\mathrm{HA}_{7}$} & 2 & 18609 & 101.9 & 4.7 & $0.39-0.77$ & 45.5 \\
\hline & 3 & 18732 & 102.0 & 4.8 & $0.79-0.93$ & 45.6 \\
\hline & 1 & 12289 & 81.1 & 0.0 & 0.82 & 39.2 \\
\hline \multirow[t]{2}{*}{$\mathrm{HA}_{9}$} & 2 & 9386 & 84.4 & 3.3 & $0.29-0.70$ & 36.6 \\
\hline & 3 & 10652 & 85.7 & 4.6 & $0.86-0.95$ & 39.0 \\
\hline
\end{tabular}

Table 2. Parameter estimates and uncertainties for Michaelis Menten kinetic constants for elongation reactions of various lengths of hyaluronic acid.

\begin{tabular}{cccc}
\hline Reaction substrate & $k_{\text {cat }}\left(\mathrm{s}^{-1}\right)$ & $K_{\mathrm{M}}(\mathrm{mM})$ & $k_{\text {cat }} / K_{\mathrm{M}}\left(\mathrm{mM}^{-1} \cdot \mathrm{s}^{-1}\right)$ \\
\hline $\mathrm{HA}_{4}$ & $4.6 \pm 0.2$ & $0.5 \pm 0.1$ & $8.7 \pm 0.2$ \\
$\mathrm{HA}_{6}$ & $9.9 \pm 0.7$ & $0.9 \pm 0.2$ & $10.7 \pm 0.2$ \\
$\mathrm{HA}_{8}$ & $10.8 \pm 0.8$ & $1.6 \pm 0.3$ & $6.9 \pm 0.2$ \\
$\mathrm{HA}_{5}$ & $8.7 \pm 0.5$ & $0.8 \pm 0.17$ & $10.8 \pm 0.2$ \\
$\mathrm{HA}_{7}$ & $14.0 \pm 0.6$ & $0.3 \pm 0.07$ & $44.4 \pm 0.1$ \\
$\mathrm{HA}_{9}$ & $13.8 \pm 0.7$ & $0.4 \pm 0.08$ & $34.1 \pm 0.2$ \\
\hline
\end{tabular}

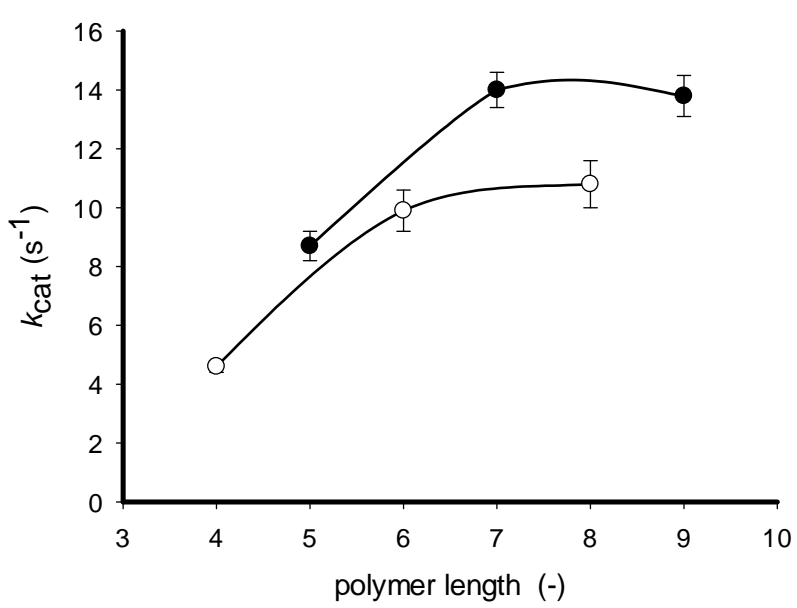

Figure 3. Relation between turnover number $k_{\text {cat }}$ and oligomer length for odd-numbered and even-numbered oligomers. Lines are for visual guidance only.

$1 \mathrm{mM}$ UDP-GlcNAc reported in literature [39].

Interestingly, there is a significant difference between $K_{\mathrm{M}}$ 's of the even-numbered and odd-numbered oligosac- 
charides. The $K_{\mathrm{M}}$ 's of the odd-numbered oligosaccharides are decreasing with the increase of the chain length, while, on the contrary, those for the even-numbered increase. Understanding these trends is accomplished by assessing the differences in the specificity constant $k_{\text {cat }} / K_{\mathrm{M}}$ between even-numbered and odd-numbered oligosaccharides. The specificity constant $k_{\text {cat }} / K_{\mathrm{M}}$ contains the affinity $1 / K_{\mathrm{M}}$ of the enzyme towards substrates $[34,48]$ and is seen to increases (Table 2) from 10.8 to 44.4 $\mathrm{mM}^{-1} \cdot \mathrm{s}^{-1}$ for $\mathrm{HA}_{5}$ and $\mathrm{HA}_{7}$; after that, a slight decrease is observed to $34.1 \mathrm{mM}{ }^{-1} \cdot \mathrm{s}^{-1}$ for $\mathrm{HA}_{9}$. This suggests that the two sugar residues at the reducing end of $\mathrm{HA}_{7}$ (GlcUA2-GlcNAc1), compared to $\mathrm{HA}_{5}$, enhance the binding to the oligosaccharide site by interacting more strongly. The specificity constant of $\mathrm{HA}_{9}$ does not increase further; apparently, it does not develop additional interactions with the binding site. By investigating initial polymerization rates of HA acceptor analogs up to hexasaccharides, Williams et al. [39] demonstrated that the minimal oligosaccharide length for high-efficiency elongation is comprised of, at the least, a trisaccharide with two glucuronic acid residues. This indicates that the oligosaccharide binding site at the UA-transferase site has the capacity to bind a minimum of three saccharide residues, as suggested by Williams [39], and a maximum of seven saccharide residues, as proposed in this study.

Contradictorily, the $k_{\text {cat }} / K_{\mathrm{M}}$ value for even-numbered oligosaccharides is moderately constant ranging from 6.9 to $10.7 \mathrm{mM} \mathrm{m}^{-1} \cdot \mathrm{s}^{-1}$. The variance in binding specificity of PmHAS for odd and even-numbered oligosaccharides would be difficult to understand if there was only one oligosaccharide binding site in PmHAS at which both elongations (NAc and UA) would occur. These differences can only be explicated by two separate oligosaccharide binding sites for odd and even-numbered oligosaccharides. A long oligosaccharide binding site at the UA-transferase site could explain the increased specificity constant for $\mathrm{HA}_{7}$, whereas the moderately constant specificity constant of $\mathrm{HA}_{4}, \mathrm{HA}_{6}$ and $\mathrm{HA}_{8}$ can be explained by a short oligosaccharide binding site interacting with the first four sugar residues of $\mathrm{HA}_{4}, \mathrm{HA}_{6}$ and $\mathrm{HA}_{8}$ at the NAc-transferase site.

\subsubsection{Competition Studies}

To further examine the difference in binding specificity for odd-numbered and even-numbered oligosaccharides, we conducted competition studies to investigate 1) the influence of $\mathrm{HA}_{5}$ as an inhibitor of $\mathrm{HA}_{4}$ elongation with UDP-GlcNAc, 2) the influence of $\mathrm{HA}_{4}$ as an inhibitor of $\mathrm{HA}_{5}$ elongation with UDP-GlcUA, and 3) the competition between $\mathrm{HA}_{4}$ and $\mathrm{HA}_{6}$ for NAc-transferase activity. For each individual step elongation, enzyme activity in the absence of the competing oligosaccharide was measured as a reference. Two reactions were conducted with a molar ratio between the reacting and competing oligosaccharide of $1: 1$ or $1: 10$ (Figure 4). Theoretically, if only a single oligosaccharide binding site was evident, the reacting and competing oligosaccharides would concurrently bind, and are therefore compete for the site. If two oligosaccharide binding sites were evident, a competing oligosaccharide $\left(\mathrm{HA}_{4}\right.$ or $\left.\mathrm{HA}_{5}\right)$ might still bind non-productively at the elongation site, since these competitors only differ from the reacting oligosaccharide in the last sugar at the non-reducing end. In both cases, the competing oligosaccharide binds at the reacting site, and the measured activity should decrease compared to the reference reaction.

The results in Figure 4(A) show that $\mathrm{HA}_{5}$ does not influence the reaction between $\mathrm{HA}_{4}$ with UDP-GlcNAc, nor does $\mathrm{HA}_{4}$ create variation with the rates of the reaction between $\mathrm{HA}_{5}$ with UDP-GlcUA. The absence of competition confirms that there are two separate oligosaccharide binding sites within PmHAS, one for each transferase activity, and that these binding sites are very specific for their substrates. Previously, Williams et al. [39] had also observed absence of competition for a particular class of longer oligosaccharides $\left(\mathrm{HA}_{14}\right.$ and $\left.\mathrm{HA}_{15}\right)$.

Both $\mathrm{HA}_{4}$ and $\mathrm{HA}_{6}$ oligosaccharides can react with UDP-GlcNAc at the same site, and this is confirmed by the experimental outcomes. The reaction rate measured in experiments with both substrates simultaneously equals the sum of the individual elongation rates of $\mathrm{HA}_{4}$ and $\mathrm{HA}_{6}$ (Figure 4(B)). The specificity constants of $\mathrm{HA}_{4}$ and $\mathrm{HA}_{6}$ are generally the same, which is the result of approximately twice as high $K_{\mathrm{M}}$ and $k_{\text {cat }}$ values for $\mathrm{HA}_{6}$ compared to the $K_{\mathrm{M}}$ and $k_{\text {cat }}$ values of $\mathrm{HA}_{4}$ (see Table 2). In the reactions with $3 \mathrm{mM} \mathrm{HA}_{4}$, i.e. the equivalent of $6 \cdot K_{\mathrm{M}}$ of $\mathrm{HA}_{4}$, the $k_{\text {cat }}$ is almost attained for the $\mathrm{HA}_{4}$ reactions, corresponding to a specific activity of $177 \mu \mathrm{mol} /$ $\mathrm{mg} \cdot \mathrm{hr}$ (see Figure $\mathbf{4}$ and the last two white bars in Figure 4(B)). The specific activity (see second to last white bar in Figure 4(B)) increased, moreover, to $213 \mu \mathrm{mol} /$ $\mathrm{mg} \cdot \mathrm{hr}$ by the addition of $0.3 \mathrm{mM} \mathrm{HA}_{6}$. On the contrary, the $k_{\text {cat }}$ of $\mathrm{HA}_{6}$ is not attained, since $3 \mathrm{mM} \mathrm{HA}_{6}$, the equivalent of $\sim 3 * K_{\mathrm{M}}$ of $\mathrm{HA}_{6}$, is not sufficient to achieve saturating concentrations (last two grey bars in Figure 4(B)). The results from the competition studies between $\mathrm{HA}_{4}$ and $\mathrm{HA}_{6}$ thus demonstrate that elongation of these two oligosaccharides is dependent on their concentration levels and that, under the current conditions, the combined rate is the sum of the individual rates.

\subsection{Structural Characteristics}

A three-dimensional model of PmHAS was constructed based on the recently obtained crystal structure of K4CP chondroitin polymerase [29], which exhibits a sequence identity of $62 \%$ and sequence homology of 79\% compared to PmHAS. The Ramachandran plot ob- 


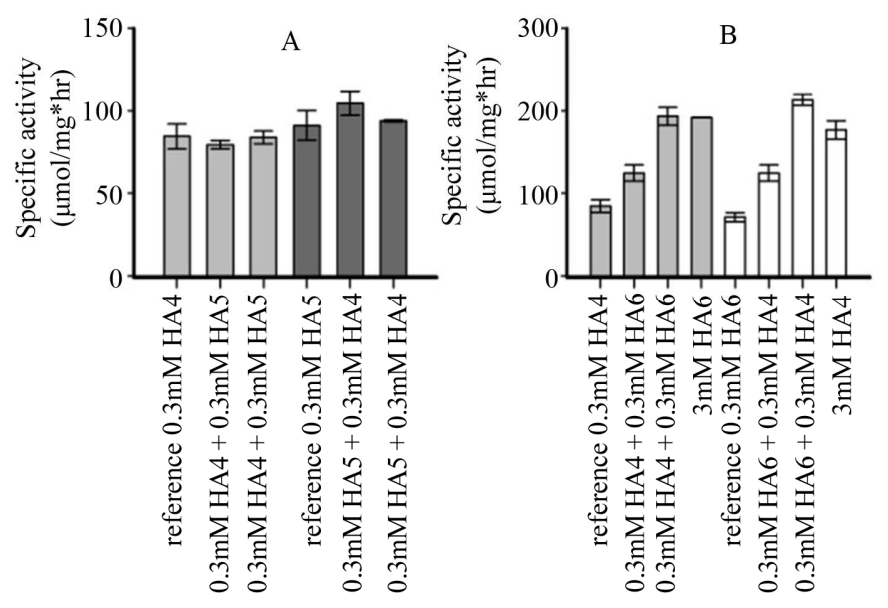

Figure 4. Influence of the competing oligosaccharide on the PmHAS elongation reaction. (A) The light grey bars show the results of $\mathrm{HA}_{5}$ as competitor to the elongation reaction of $\mathrm{HA}_{4}$ with UDP-GlcNAc, whereas the dark grey depicts the $\mathrm{HA}_{5}$ elongation reaction with UDP-GlcUA and competing oligosaccharide $\mathrm{HA}_{4}$; (B) The results of $\mathrm{HA}_{6}$ as "competing" oligosaccharide are shown in grey, and for $\mathrm{HA}_{4}$ in white.

tained from PROCHECK demonstrated that the stereochemical quality of the model was very valuable. Only two residues, $\mathrm{Ala}^{310}$ and $\mathrm{Asn}^{411}$, show slightly deviating Phi and Psi angles that do not project consequences on the overall structure; both of these residues are in flexible loops. The structure of PmHAS residues 72 to 688 is almost identical to the $\mathrm{K} 4 \mathrm{CP}$ structure ( $c f$. the overlay of the two structures, Figure 5(A)); only the last 15 residues $(689$ - 703) could not be modeled. This structural model thus allows localization of the two oligosaccharide binding sites that were inferred from the kinetic studies.

PmHAS consists of three domains (Figure 5(B)): an $\mathrm{N}$-terminal domain (residues 72 to 134); the NAc-transferase-domain (residues 135 to 426); and the UA-transferase domain (residues 427 - 688). The N-terminal domain consists of a random coil and two $\alpha$-helices, and the first 71 residues are missing as no alignment could be discerned for this N-terminal region. The NAc-transferase domain of PmHAS contains $13 \alpha$-helices and 12 $\beta$-strands. The UA-transferase domain consists of 10 $\alpha$-helices and $12 \beta$-strands as with the structure of K4CP. Both the NAc-transferase and the UA-transferase domains of PmHAS adopt the GT-A fold, which consists of an $\alpha / \beta / \alpha$ sandwich and is one of the fold types in glycolsyltransferases [49] (Figure 5). The orientation of the two active sites and the substantial distance of over $60 \AA$ make a single oligosaccharide binding site within PmHAS unlikely (Figure 5).

The PmHAS model was further analyzed for structural alignment with GT-A folded glycosyltransferases to identify conserved regions in structure and sequence. Conserved regions, such as amino acid residues involved in binding substrates, are frequently important in enzyme functionality. Below, similarities in substrate binding and substrate orientation are employed to ascertain binding sites of HA oligosaccharides in PmHAS. Various GT-A folded glycosyltransferases were structurally aligned with PmHAS (abbreviations in parentheses): UDPGalNAc:polypeptide $\alpha$-N-acetylgalactosaminyl-transferase $\mathrm{T} 2$ (hT2, [50]), $\beta 1$,3-glucuronosyltransferase (GlcAT1, [51]), $\beta 1,3$-glucuronosyltransferase (GlcAT-P, [52]), $\beta 1$, 4-galactosyltransferase ( $\beta 4 \mathrm{Gal}-\mathrm{T} 1,[53]), \alpha 1,4-\mathrm{N}$-acetylhexosaminlytransferase (EXTL2, [54]), $\alpha 1,3$-galactosyltransferase ( $\alpha 3 \mathrm{GT}$, [55]), blood group A $\alpha 1,3-\mathrm{N}-$ galactosaminyltransferase (hGTA, [56]), $\alpha 1$,4-galactosyltransferase (LgtC, [57]).

\subsubsection{UDP-Sugar Binding Site}

Although the structurally aligned enzymes represent a broad spectrum of glycosyltransferase reactions, regions that bind the UDP-sugars are conserved, resulting in strong similarities such as the orientation of the UDPsugar in the site (Figure 6). The DXD motif $[58,59]$ is extremely conserved within GT-A folded glycosyltransferases and forms a complex with divalent ions, such as $\mathrm{Mn}^{2+}$ and $\mathrm{Mg}^{2+}$, which are crucial for UDP-sugar binding. The DXD motif in PmHAS is defined as $\mathrm{Asp}^{247}$, $\mathrm{Cys}^{248}$ and $\mathrm{Asp}^{249}$ within the NAc-transferase site and $\mathrm{Asp}^{527}$, $\mathrm{Ser}^{528}$, and $\mathrm{Asp}^{529}$ within the UA-transferase site. Mutation studies within PmHAS have exhibited that varying any of these Asp residues deactivates the transferase site containing that DXD motif [60]. In addition, the DGS motif in PmHAS contains an Asp residue that is conserved in certain aligned glycosyltransferases as well. 


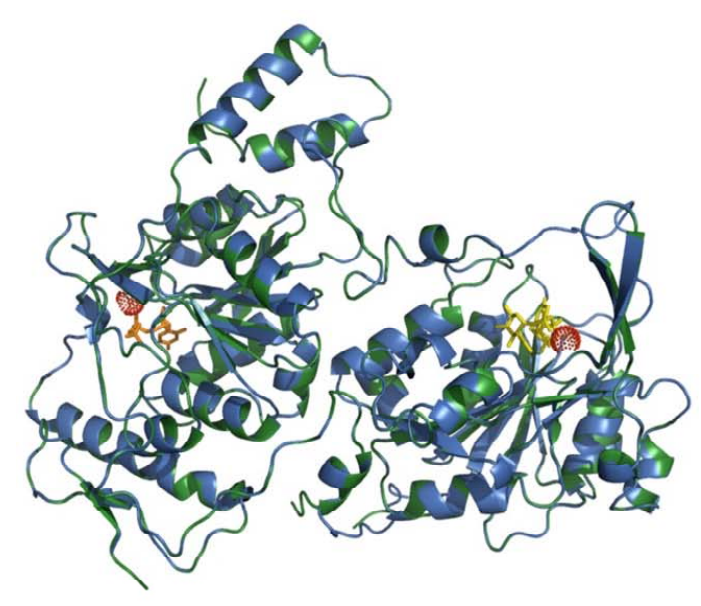

(A)

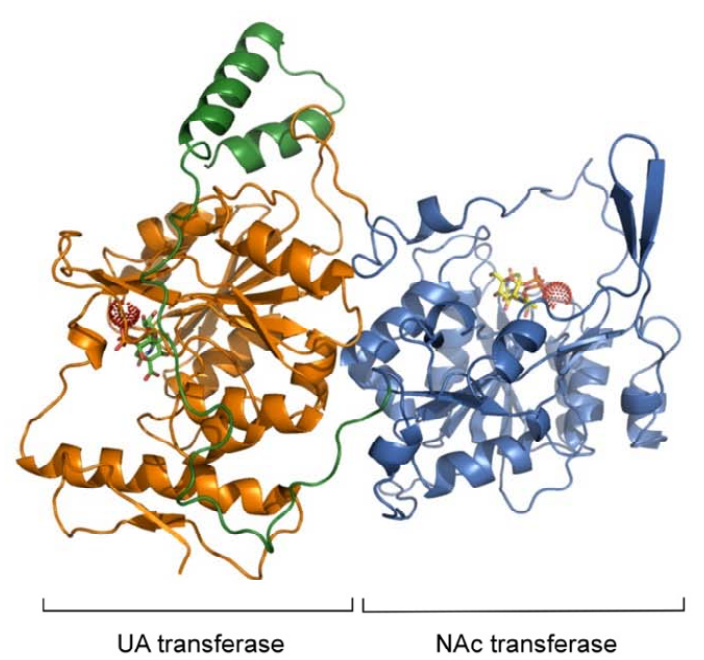

(B)

Figure 5. Structural homology model of PmHAS. (A) Superimposition of the crystal structure of K4CP chondroitin polymerase (green) and the PmHAS homology model (blue) with RMSD value and Z-score of $0.5 \AA$ and 53.4, respectively. Substrates UDP (orange) and UDP-GalNAc (yellow), depicted as sticks, and $\mathrm{Mn}^{2+}$, as red dots, were originally present in the crystal structure. Secondary structural elements are indicated by ribbons for $\alpha$-helices, and arrows for $\beta$-strands. (B) Overall structure of PmHAS with UDP-GlcUA (green) and UDP-GlcNAc (yellow) in sticks and $\mathrm{Mn}^{2+}$ as red dots. The structure is divided in three domains: the N-terminal region (residues 72 - 134) in green, the UA-transferase (427 - 688) in orange and the NActransferase $(135-426)$ in blue.

This Asp residue interacts with the N3 of the uracyl group within the UDP moiety. Mutation of $\mathrm{Asp}^{196}$ or $\mathrm{Asp}^{477}$ in PmHAS resulted in loss of NAc- or UA-transferase activity [30], respectively, which emphasizes the importance of these residues.

\subsubsection{Acceptor Binding Site}

Since PmHAS contains $\beta 1,3$-glucuronyltransferase and $\beta 1,4-N$-acetylglucosaminyltransferase domains, the aligned glycosyltransferases were selected on the basis of the ability to elongate the acceptor at the $3 \mathrm{OH}$ or $4 \mathrm{OH}$ group with the donor sugar. The structural alignments indicate that the acceptor has distinct orientations towards the UDP-sugar, depending on the type of linkage formed following the sugar moiety transfer (Figure 6). The $\alpha$-configuration of the $\mathrm{C} 1$ in the sugar moiety attached to UDP is preserved in the product after the conveyance by retaining glycosyltransferases, whereas inverting glycosyltransferases convert this into a $\beta$-linked product. Consequently, the attacking $\mathrm{OH}$ group in the acceptor in retaining enzymes is arranged sequentially to the $\mathrm{C} 1$ of the sugar moiety, ready to form the $\alpha$-linkage (Figures 6(B) and (D)). Similarly, the attacking $\mathrm{OH}$ group in inverting glycosyltransferases is positioned opposite to the $\alpha$-linked UDP (Figures 6(A) and (C)). This is emphasized by the reported hydrogen bonds in retaining glycosyltransferases between the attacking $\mathrm{OH}$ group in the acceptor and an oxygen atom of the $\beta$-phosphate group in UDP $[55-57,64]$. These hydrogen bonds were not evident in inverting enzymes, where the distance between UDP and the acceptor is too extensive.

In addition to the similarities in acceptor orientation, aromatic hydrophobic residues Phe, Trp, and Tyr are located near every catalytic center. Their roles in the acceptor binding site appear to depend on their location and orientation within the active site. Mutation studies in the aligned glycosyltransferases illustrate that aromatic hydrophobic residues exhibit specific affinity towards the acceptor $[65,66]$, perform as a stabilizer of the transition state [66], or assist in the orientation of the acceptor into the correct position [53].

\subsubsection{Oligosaccharide Positioning}

Structural similarities among PmHAS and other glycosyltransferases demonstrated that the HA oligosaccharide should be positioned underneath the $\mathrm{C} 1$ of the sugar moiety to form $\beta$-linkages, since PmHAS has two inverting transferase domains. AutodockVina [42] was employed to model $\mathrm{HA}_{6}$ and $\mathrm{HA}_{7}$ into the NAc-transferase and UA-transferase sites (Figure 7), respectively. The orientations of $\mathrm{HA}_{6}$ and $\mathrm{HA}_{7}$ (Figures 7(A) and (B)) concur with the results from Figure 6. Additionally, the amino acids that are likely to interact with the substrates are depicted as sticks (Figure 7).

Kinetic results indicated that there is a difference in binding specificity between the NAc-transferase and UA-transferase sites and that in the UA-transferase site the specificity constant strongly increases upon elongation 

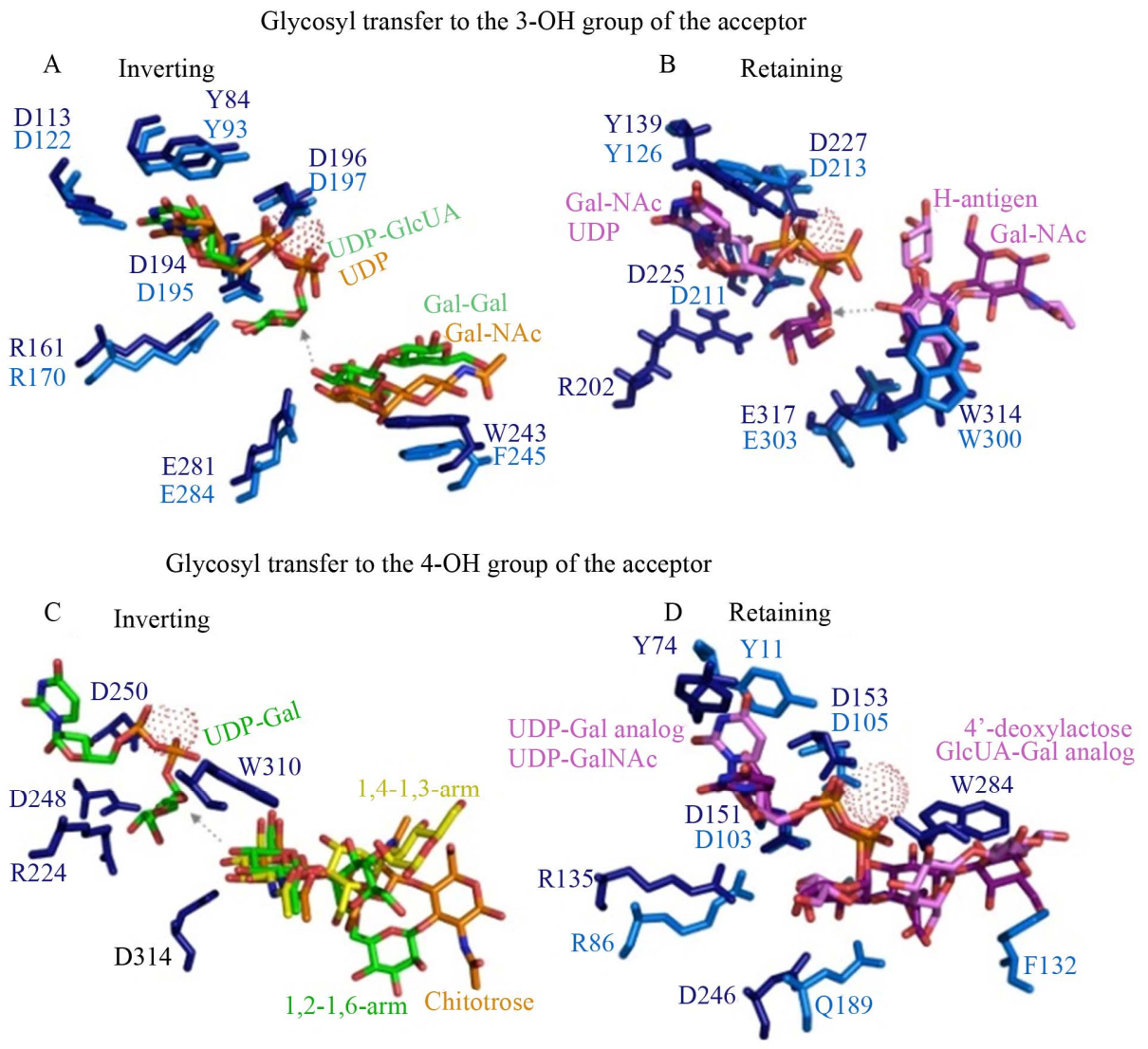

Figure 6. Substrate orientation in active sites of structurally aligned glycosyltransferases of the GT-A fold. Crystal structures of enzymes with both donor and acceptor substrates were superimposed to investigate the orientation of the attacking $\mathrm{OH}$ group of the acceptor toward the UDP-sugar. Grey arrows point out the direction of the reacting $\mathrm{OH}$ group to the $\mathrm{C} 1$ of the sugar moiety. The DXD motif, the proposed catalytic residue and other conserved residues are indicated. (A) inverting $\beta 1,3$-transferases GlcAT-1 in dark blue (1fgg [51] and 1kws [61], $\mathrm{Gal} \beta 1-3 \mathrm{Gal}$ and UDP-GlcUA in green) and GlcAT-P in blue (1v84 [52], N-acetyllactosamine and UDP in orange); (B) retaining $\alpha 1,3$-transferases $\alpha 3 \mathrm{GT}$ in dark blue (1o7q [55] and 1g93 [62], N-acetyllactosamine and UDP-Gal in purple) and hGTA in blue (1lzi [56], H-antigen and UDP in pink); (C) inverting $\beta 1,4$-transferase $\beta 4$ Gal-T1 in dark blue (1tvy [63], UDP-Gal in green) with three acceptors (chitotriose in orange, 2ah9 [53]; trisaccharideGlcNAc $\beta 1,2-$ $\operatorname{Man} \alpha 1,6-\mathrm{Man} \beta$-OR (1,2-1,6-arm) in green, 2aec [53]; trisaccha-rideGlcNAc $\beta 1,4-M a n \alpha 1$, 3 -Man $\beta$-OR (1,4-1,3-arm) in orange, 2agd); (D) retaining $\alpha 1,4$ - transferases EXTL2 in dark blue (1on8 and 1on6 [54], GlcUA $\beta 1$-3Gal $\beta 1$-O-naphthale-nemethanol and UDP-GalNAc in purple), and LgtC in blue (1ga8 [57], 4'-deoxylactose and UDP-2-deoxy-2fluoro-galactose in pink).

from $\mathrm{HA}_{5}$ to $\mathrm{HA}_{7}$. Both results can be explained by the structural model. First, the channel-shaped oligosaccharide binding site in the UA-transferase site is longer than in the NAc-transferase site (Figure 7(C)). At the NAc-transferase site, only the first four sugar residues at the non-reducing end of $\mathrm{HA}_{6}$ are in direct contact with amino acid residues in the oligosaccharide site; other sugar residues have considerable additional degrees of freedom without amino acid interactions. In addition, all sugar residues of $\mathrm{HA}_{7}$ at the UA-transferase site are encompassed by the oligosaccharide binding site, resulting in a higher specificity constant than for $\mathrm{HA}_{5}$.

\subsection{Polydispersity}

Present kinetic parameters were utilized to monitor the effect of $\mathrm{HA}_{4}$ concentration on the polydispersity of the HA products over time. Two situations were selected, specifically, a polymerization reaction with the concentration of the oligosaccharide acceptor at (a) unsaturated levels $\left(K_{\mathrm{M}} / 5\right)$ and at (b) saturated levels $\left(5 \cdot K_{\mathrm{M}}\right)$. For both reactions, the UDP-sugars were at saturated concentrations of $2 \mathrm{mM}$ UDP-GlcUA and $40 \mathrm{mM}$ UDP-GlcNAc, respectively. To visualize all products, $\mathrm{HA}_{4}$ labeled with anthranillic acid ( $\mathrm{HA}_{4}$-fluor) was used for polymerization. Since in a previous study [33], we established that $\mathrm{HA}_{4}{ }^{-}$ 

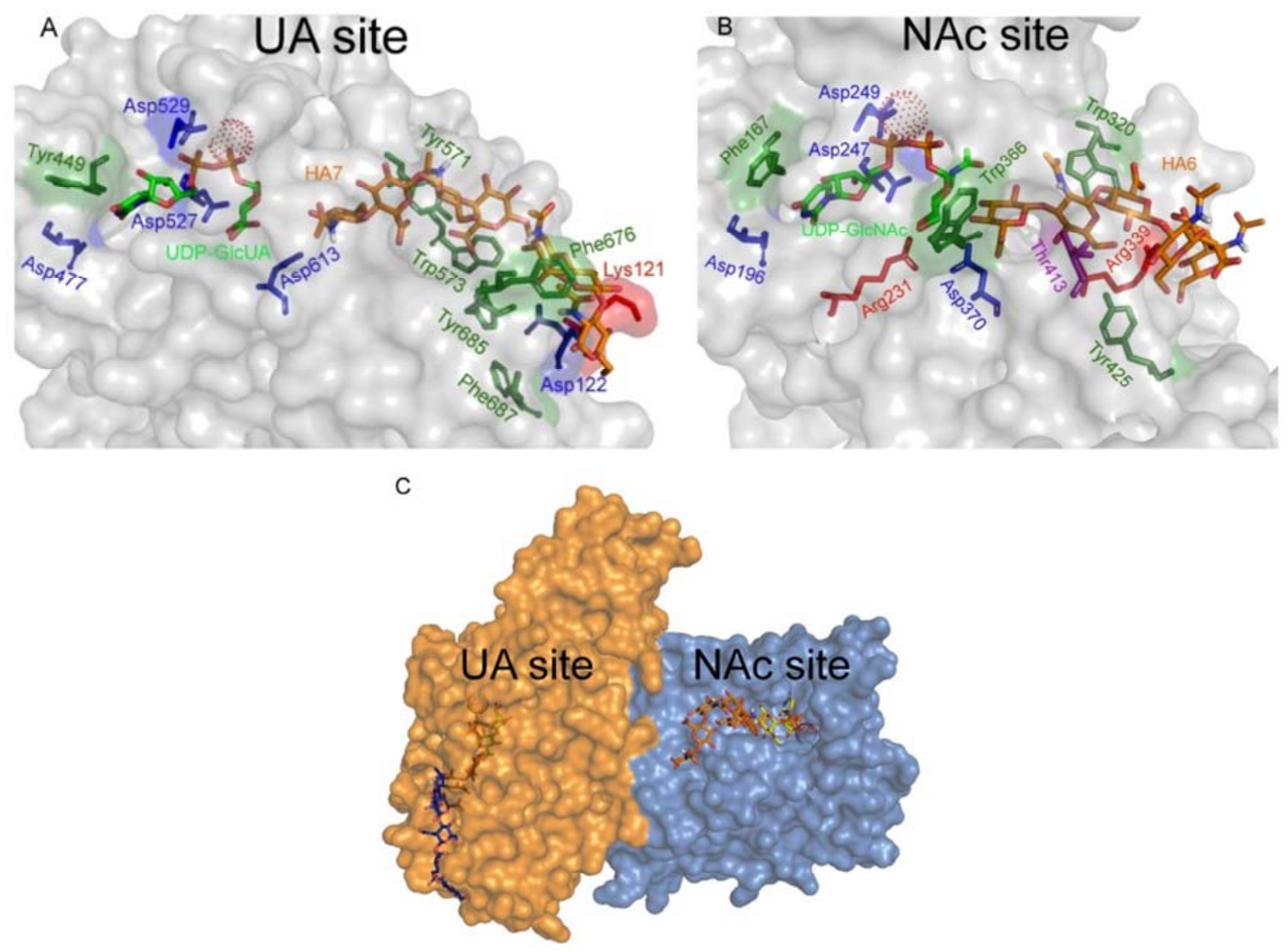

Figure 7. Docking of HA oligosaccharides in the PmHAS active sites. On top are the results shown for the UA-transferase site with a heptasaccharide $\left(\mathrm{HA}_{7}\right)$ modeled into the active site and, vice versa, the results for the NAc-transferase with a hexasaccharide $\left(\mathrm{HA}_{6}\right)$ below. The orientation of the acceptors towards the UDP-sugars is demonstrated in (A) and (B), and an overview of the PmHAS struc- ture with the two acceptor binding sites is given in $(\mathrm{C})$. The surface of PmHAS is made transparent to show the substrate orientation and the amino acid residues that are most likely involved in substrate binding (shown in sticks).

fluor and $\mathrm{HA}_{4}$ are kinetically similar, we assumed that $\mathrm{HA}_{4}$-fluor and $\mathrm{HA}_{4}$ have comparable $K_{\mathrm{M}}$ values.

In Figure 8, the polydispersity is seen to increase over time for both reactions with significantly more $\mathrm{HA}$ products in reactions with unsaturated $\mathrm{HA}_{4}$-fluor concentrations.

This result is in agreement with data of Mulders and Beeftink, who theoretically demonstrated the size distribution to be more prominent at higher reaction orders in HA concentration [67]. The observed increase in polydispersity over time is the effect of elongation at two separate active sites. Oligosaccharide elongation in PmHAS can only occur by the sequential binding, elongation and release of the growing HA chain. Since the two oligosaccharide binding sites in PmHAS are a considerable distance from each other, the HA oligosaccharide extended at one transferase site is not immediately extended by the other. At unsaturated $\mathrm{HA}_{4}$-fluor concentrations, this effect is magnified because complex forma-
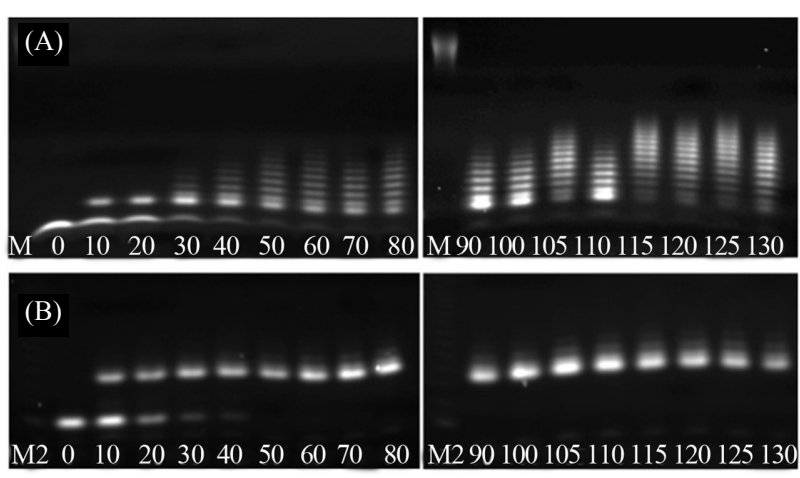

Figure 8. Influence of $\mathrm{HA}_{4}$-fluor concentration on product polydispersity over time. Reactions were followed for $130 \mathrm{~min}$ and analyzed on $20 \%$ TBE polyacrylamidegel. (a) Reactions containing $0.1 \mathrm{mM} \mathrm{HA}_{4}$-fluor, $2 \mathrm{mM}$ UDP-GlcUA, $40 \mathrm{mM}$ UDP-GlcNAc and $15 \mu \mathrm{g} / \mathrm{ml}$ PmHAS. (b) Reactions containing $2.5 \mathrm{mM} \mathrm{HA}_{4}$-fluor, $2 \mathrm{mM}$ UDP-GlcUA, $40 \mathrm{mM}$ UDP-GlcNAc and $30 \mu \mathrm{g} / \mathrm{ml} \mathrm{PmHAS.} \mathrm{M}$ and M2 are other reactions with $\mathrm{HA}_{4}$-fluor used as markers. 
tion between PmHAS and $\mathrm{HA}_{4}$-fluor is decelerated, resulting in an increased polydispersity. Polydispersity of HA products can be decreased by controlling the initial concentrations of HA oligosaccharide and UDP-sugars.

\section{CONCLUSION}

Evidence is presented for two separate oligosaccharide binding sites within PmHAS, one in each transferase domain. Based on kinetic and structural analysis, we demonstrate that the two transferase domains act as two independent enzymes, where GlcNAc is transferred at the NAc-transferase domain and GlcUA at the UAtransferase domain. The transferase domains in PmHAS indicate structural similarity with glycosyltransferases of the GT-A fold. With structural alignment of these enzymes, we identified general characteristics of acceptor binding sites in these enzymes that are useful in locating oligosaccharide binding sites in other GT-A folded glycosyltransferases. We propose two locations for these oligosaccharide binding sites that are considerably distant from each other. As a result of this extensive distance, the number of products will increase over time in a polymerization reaction unless single-step reactions are imposed. The molecular weight and polydispersity of the product can be controlled by the availability of the substrates.

\section{ACKNOWLEDGEMENTS}

The authors thank Jan Springer and Aukje Zimmerman for the production of PmHAS; Martinus van Boekel for helpful discussions on statistical analysis; and Lambertus van den Broek for technical assistance with MALDI-TOF MS experiments.

The project is a collaboration with Merck \& Co. (formerly Organon N.V.) and financially supported by the Netherlands Ministry of Economic Affairs and B-Basic partners (www.b-basic.nl) through B-Basic, a public-private NWO-ACTS program (ACTS = Advanced Chemical Technologies for Sustainability).

\section{REFERENCES}

[1] Gandhi, N.S. and Mancera, R.L. (2008) The structure of glycosaminoglycans and their interactions with proteins. Chemical Biology \& Drug Design, 72, 455-482. http://dx.doi.org/10.1111/j.1747-0285.2008.00741.x

[2] Schaefer, L. and Schaefer, R.M. (2010) Proteoglycans: From structural compounds to signaling molecules. Cell and Tissue Research, 339, 237-246. http://dx.doi.org/10.1007/s00441-009-0821-y

[3] Stern, R. (2008) Association between cancer and "acid mucopolysaccharides": An old concept comes of age, finally. Seminars in Cancer Biology, 18, 238-243. http://dx.doi.org/10.1016/j.semcancer.2008.03.014

[4] Meyer, K. and Palmer, J.W. (1934) The polysaccharide of the vitreous humor. Journal of Biological Chemistry, 107,
629-634.

[5] Boas, N.F. (1949) Isolation of hyaluronic acid from the cock's comb. Journal of Biological Chemistry, 181, 573575.

[6] Meyer, K. and Chaffee, E. (1941) The mucopolysaccharides of skin. Journal of Biological Chemistry, 138, 491-499.

[7] Chain, E. and Duthie, E.S. (1940) Identity of hyaluronidase and spreading factor. British Journal of Experimental Pathology, 21, 324-338.

[8] Kendall, F.E., Heidelberger, M. and Dawson, M.H. (1937) A serologically inactive polysaccharide elaborated by mucoid strains of group A hemolytic streptococcus. Journal of Biological Chemistry, 118, 61-69.

[9] Carter, G.R. and Annau, E. (1953) Isolation of capsular polysaccharides for colonial variants of Pasteurella multocida. American Journal of Veterinary Research, 14, 475-478.

[10] MacLennan, A.P. (1956) The production of capsules, hyaluronic acid and hyaluronidase by 25 strains of group C streptococci. Journal of General Microbiology, 15, 485-491. http://dx.doi.org/10.1099/00221287-15-3-485

[11] Thonard, J.C., Migliore, S.A. and Blustein, R. (1964) Isolation of hyaluronic acid from broth cultures of streptococci. Journal of Biological Chemistry, 239, 726-728.

[12] Armstrong, D.C. and Johns, M.R. (1997) Culture conditions affect the molecular weight properties of hyaluronic acid produced by Streptococcus zooepidemicus. Applied \& Environmental Microbiology, 63, 27592764.

[13] Widner, B., et al. (2005) Hyaluronic acid production in Bacillus subtilis. Applied \& Environmental Microbiology, 71, 3747-3752. http://dx.doi.org/10.1128/AEM.71.7.3747-3752.2005

[14] DeAngelis, P.L., Papaconstantinou, J. and Weigel, P.H. (1993) Isolation of a Streptococcus pyogenes gene locus that directs hyaluronan biosynthesis in acapsular mutants and in heterologous bacteria. Journal of Biological Chemistry, 268, 14568-14571.

[15] Chien, L.-J. and Lee, C.-K. (2007) Hyaluronic acid production by recombinant Lactococcus lactis. Applied Microbiology and Biotechnology, 77, 339-346. http://dx.doi.org/10.1007/s00253-007-1153-z

[16] Yu, H. and Stephanopoulos, G. (2008) Metabolic engineering of Escherichia coli for biosynthesis of hyaluronic acid. Metabolic Engineering, 10, 24-32. http://dx.doi.org/10.1016/j.ymben.2007.09.001

[17] Mao, Z. and Chen, R.R. (2007) Recombinant synthesis of hyaluronan by agrobacterium sp. Biotechnology Progress, 23, 1038-1042.

[18] Mao, Z., Shin, H.-D. and Chen, R. (2009) A recombinant E. coli bioprocess for hyaluronan synthesis. Applied Microbiology and Biotechnology, 84, 63-69. http://dx.doi.org/10.1007/s00253-009-1963-2

[19] Johns, M.R., Goh, L.-T. and Oeggerli, A. (1994) Effect of $\mathrm{pH}$, agitation and aeration on hyaluronic acid production by Streptococcus zooepidemicus. Biotechnology Letters, 16, 507-512. http://dx.doi.org/10.1007/BF01023334 
[20] Huang, W.-C., Chen, S.-J. and Chen, T.-L. (2006) The role of dissolved oxygen and function of agitation in hyaluronic acid fermentation. Biochemical Engineering Journal, 32, 239-243.

http://dx.doi.org/10.1016/j.bej.2006.10.011

[21] Kim, J.-H., et al. (1996) Selection of a Streptococcus equi mutant and optimization of culture conditions for the production of high molecular weight hyaluronic acid. Enzyme and Microbial Technology, 19, 440-445. http://dx.doi.org/10.1016/S0141-0229(96)00019-1

[22] Chen, W.Y., et al. (2009) Hyaluronan molecular weight is controlled by UDP-N-acetylglucosamine concentration in Streptococcus zooepidemicus. Journal of Biological Chemistry, 284, 18007-18014. http://dx.doi.org/10.1074/jbc.M109.011999

[23] Krupa, J.C., et al. (2007) Quantitative continuous assay for hyaluronan synthase. Analytical Biochemistry, 361, 218-225. http://dx.doi.org/10.1016/j.ab.2006.11.011

[24] Pummill, P.E., Achyuthan, A.M. and DeAngelis, P.L. (1998) Enzymological characterization of recombinant Xenopus DG42, a vertebrate hyaluronan synthase. Journal of Biological Chemistry, 273, 4976-4981. http://dx.doi.org/10.1074/jbc.273.9.4976

[25] Itano, N., et al. (1999) Three isoforms of mammalian hyaluronan synthases have distinct enzymatic properties. Journal of Biological Chemistry, 274, 25085-25092. http://dx.doi.org/10.1074/jbc.274.35.25085

[26] Tlapak-Simmons, V.L., et al. (1999) Kinetic characterization of the recombinant hyaluronan synthases from Streptococcus pyogenes and Streptococcus equisimilis. Journal of Biological Chemistry, 274, 4246-4253. http://dx.doi.org/10.1074/jbc.274.7.4246

[27] DeAngelis, P.L. (1999) Molecular directionality of polysaccharide polymerization by the Pasteurella multocida hyaluronan synthase. Journal of Biological Chemistry, 274, 26557-26562.

http://dx.doi.org/10.1074/jbc.274.37.26557

[28] Jing, W. and DeAngelis, P.L. (2004) Synchronized chemoenzymatic synthesis of monodisperse hyaluronan polymers. Journal of Biological Chemistry, 279, 4234542349. http://dx.doi.org/10.1074/jbc.M402744200

[29] Osawa, T., et al. (2009) Crystal structure of chondroitin polymerase from Escherichia coli K4. Biochemical and Biophysical Research Communications, 378, 10-14. http://dx.doi.org/10.1016/j.bbrc.2008.08.121

[30] Jing, W. and DeAngelis, P.L. (2000) Dissection of the two transferase activities of the Pasteurella multocida hyaluronan synthase: Two active sites exist in one polypeptide. Glycobiology, 10, 883-889. http://dx.doi.org/10.1093/glycob/10.9.883

[31] Fitzgerald, D.K., et al. (1970) Enzymic assay for galactosyl transferase activity of lactose synthetase and [alpha]lactalbumin in purified and crude systems. Analytical Biochemistry, 36, 43-61. http://dx.doi.org/10.1016/0003-2697(70)90330-1

[32] Gosselin, S., et al. (1994) A continuous spectrophotometric assay for glycosyltransferases. Analytical Biochemistry, 220, 92-97. http://dx.doi.org/10.1006/abio.1994.1303

[33] Kooy, F.K., et al. (2009) Quantification and characterization of enzymatically produced hyaluronan with fluorophore-assisted carbohydrate electrophoresis. Analytical Biochemistry, 384, 329-336. http://dx.doi.org/10.1016/j.ab.2008.09.042

[34] Cornish-Bowden, A. (1995) Fundamentals of enzyme kinetics. Portland Press Ltd., London.

[35] Cook, P.F. and Cleland, W.W. (2007) Enzyme kinetics and mechanism. Garland Science, London.

[36] De Levie, R. (2004) Macros for least-squares \& for the propagation of imprecision, in advanced excel for scientific data analysis. Oxford University Press, New York.

[37] Van Boekel, M.A.J.S. (2010) Kinetic modeling of reactions in foods. CRC Press, Boca Raton.

[38] Motulsky, H. and Christopoulos, A. (2003) Fitting models to biological data using linear and nonlinear regression: A practical guide to curve fitting. GraphPad Software Inc., San Diego.

[39] Williams, K.J., Halkes, K.M., Kamerling, J.P. and DeAngelis, P.L. (2006) Critical elements of oligosaccharide acceptor substrates for the Pasteurella multocida hyaluronan synthase. Journal of Biological Chemistry, 281, 53915397. http://dx.doi.org/10.1074/jbc.M510439200

[40] Laskowski, R.A., MacArthur, M.W., Moss, D.S. and Thornton, J.M. (1993) PROCHECK: A program to check the stereochemical quality of protein structures. Journal of Applied Crystalography, 26, 283-291. http://dx.doi.org/10.1107/S0021889892009944

[41] Sippl, M.J. (1993) Recognition of errors in three-dimensional structures of proteins. Proteins: Structure, Function, and Genetics, 17, 355-362. http://dx.doi.org/10.1002/prot.340170404

[42] Trott, O. and Olson, A.J. (2009) AutoDock Vina: Improving the speed and accuracy of docking with a new scoring function, efficient optimization, and multithreading. Journal of Computational Chemistry, 31, 455-461.

[43] Holm, L. and Sander, C. (1996) Mapping the protein universe. Science, 273, 595-602.

http://dx.doi.org/10.1126/science.273.5275.595

[44] DeAngelis, P.L. (1996) Enzymological characterization of the Pasteurella multocida hyaluronic acid synthase. Biochemistry, 35, 9768-9771. http://dx.doi.org/10.1021/bi960154k

[45] Tlapak-Simmons, V.L., Baron, C.A. and Weigel, P.H. (2004) Characterization of the purified hyaluronan synthase from Streptococcus equisimilis. Biochemistry, 43, 9234-9242. http://dx.doi.org/10.1021/bi049468v

[46] Yoshida, M., Itano, N., Yamada, Y. and Kimata, K. (2000) In Vitro synthesis of hyaluronan by a single protein derived from mouse HAS1 Gene and characterization of amino acid residues essential for the activity. Journal of Biological Chemistry, 275, 497-506. http://dx.doi.org/10.1074/jbc.275.1.497

[47] Kumari, K. and Weigel, P.H. (1997) Molecular cloning, expression, and characterization of the authentic hyaluronan synthase from Group C Streptococcus equisimilis. 
Journal of Biological Chemistry, 272, 32539-32546. http://dx.doi.org/10.1074/jbc.272.51.32539

[48] Eisenthal, R., Danson, M.J. and Hough, D.W. (2007) Catalytic efficiency and $k c a t / K_{M}$ : A useful comparator? Trends in Biotechnology, 25, 247-249. http://dx.doi.org/10.1016/j.tibtech.2007.03.010

[49] Breton, C., Snajdrová, L., Jeanneau, C., Koca, J. and Imberty, A. (2006) Structures and mechanisms of glycosyltransferases. Glycobiology, 16, 29R-37R. http://dx.doi.org/10.1093/glycob/cwj016

[50] Fritz, T.A., Raman, J. and Tabak, L.A. (2006) Dynamic association between the catalytic and lectin domains of human UDP-GalNAc: Polypeptide a-N-acetylgalactosaminyltransferase-2. Journal of Biological Chemistry, 281, 8613-8619. http://dx.doi.org/10.1074/jbc.M513590200

[51] Pedersen, L.C., Tsuchida, K., Kitagawa, H., Sugahara, K., Darden, T.A. and Negishi, M. (2000) Heparan/Chondroitin sulfate biosynthesis. Structure and mechanism of human glucuronyltransferase I. Journal of Biological Chemistry, 275, 34580-34585. http://dx.doi.org/10.1074/jbc.M007399200

[52] Kakuda, S., Shiba, T., Ishiguro, M., Tagawa, H., Oka, S., Kajihara, Y., Kawasaki, T., Wakatsuki, S. and Kato, R. (2004) Structural basis for acceptor substrate recognition of a human glucuronyltransferase, GlcAT-P, an enzyme critical in the biosynthesis of the carbohydrate epitope $\mathrm{HNK}_{-1}$. Journal of Biological Chemistry, 279, 2269322703. http://dx.doi.org/10.1074/jbc.M400622200

[53] Ramasamy, V., Ramakrishnana, B., Boeggeman, E., Ratner, D.M., Seeberger, P.H. and Qasba, P.K. (2005) Oligosaccharide preferences of $\beta 1$,4-galactosyltransferase-I: Crystal structures of Met340His mutant of human $\beta 1$,4-galactosyltransferase-I with a pentasaccharide and trisaccharides of the $\mathrm{N}$-glycan moiety. Journal of Molecular Biology, 353, 53-67. http://dx.doi.org/10.1016/j.jmb.2005.07.050

[54] Pedersen, L.C., Dong, J., Taniguchi, F., Kitagawa, H., Krahn, J.M., Pedersen, L.G., Sugahara, K. and Negishi, M. (2003) Crystal structure of an 1,4-N-acetylhexosaminyltransferase (EXTL2), a member of the exostosin gene family involved in heparan sulfate biosynthesis. Journal of Biological Chemistry, 278, 14420-14428. http://dx.doi.org/10.1074/jbc.M210532200

[55] Zhang, Y., Swaminathan, G.J., Deshpande, A., Boix, E., Natesh, R., Xie, Z.H., Acharya, K.R. and Brew, K. (2003) Roles of individual enzyme - Substrate interactions by $\alpha$-1,3-galactosyltransferase in catalysis and specificity. Biochemistry, 42, 13512-13521. http://dx.doi.org/10.1021/bi035430r

[56] Patenaude, S.I., Seto, N.O., Borisova, S.N., Szpacenko, A., Marcus, S.L., Palcic, M.M. and Evans, S.V. (2002) The structural basis for specificity in human $\mathrm{ABO}(\mathrm{H})$ blood group biosynthesis. Nature Structural Biology, 9, 685-690. http://dx.doi.org/10.1038/nsb832

[57] Persson, K., Ly, H.D., Dieckelmann, M., Wakarchuk, W.W., Withers, S.G. and Strynadka, N.C.J. (2001) Crystal structure of the retaining galactosyltransferase LgtC from Neisseria meningitidis in complex with donor and acceptor sugar analogs. Nature Structural Biology, 8, 166-175. http://dx.doi.org/10.1038/84168

[58] Breton, C., Bettler, E., Joziasse, D.H., Geremia, R.A. and Imberty, A. (1998) Sequence-Function relationships of prokaryotic and eukaryotic galactosyltransferases. Journal of Biochemistry, 123, 1000-1009. http://dx.doi.org/10.1093/oxfordjournals.jbchem.a022035

[59] Tarbouriech, N., Charnock, S.J. and Davies, G.J. (2001) Three-Dimensional structures of the Mn and Mg dTDP complexes of the family GT-2 glycosyltransferase SpsA: A comparison with related NDP-sugar glycosyltransferases. Journal of Molecular Biology, 314, 655-661. http://dx.doi.org/10.1006/jmbi.2001.5159

[60] Jing, W. and DeAngelis, P.L. (2003) Analysis of the two active sites of the hyaluronan synthase and the chondroitin synthase of Pasteurella multocida. Glycobiology, 13, 661-671. http://dx.doi.org/10.1093/glycob/cwg085

[61] Pedersen, L.C., Darden, T.A. and Negishi. M. (2002) Crystal structure of b1,3-glucuronyltransferase I in complex with active donor substrate UDP-GlcUA. Journal of Biological Chemistry, 277, 21869-21873. http://dx.doi.org/10.1074/jbc.M112343200

[62] Gastinel, L.N., Bignon, C., Misra, A.K., Hindsgaul, O., Shaper, J.H. and Joziass, D.H. (2001), Bovine a1,3-galacto-syltransferase catalytic domain structure and its relationship with ABO histo-blood group and glycosphingolipid glycosyltransferases. EMBO Journal, 20, 638-649. http://dx.doi.org/10.1093/emboj/20.4.638

[63] Ramakrishnan, B., Boeggeman, E. and Qasba, P.K. (2004) Effect of the Met344His mutation on the conformational dynamics of bovine b-1,4-galactosyltransferase: Crystal structure of the Met344His mutant in complex with chitobiose. Biochemistry, 43, 12513-12522.

[64] Negishi, M., Donga, J., Dardenb, T.A., Pedersenb, L.G. and Pedersen, L.C. (2003) Glucosaminylglycan biosynthesis: What we can learn from the X-ray crystal structures of glycosyltransferases GlcAT1 and EXTL2. Biochemical and Biophysical Research Communications, 303, 393-398. http://dx.doi.org/10.1016/S0006-291X(03)00356-5

[65] Fondeur-Gelinotte, M., et al. (2007) Molecular basis for acceptor substrate specificity of the human $\beta 1,3$-glucuronosyltransferases GlcAT-I and GlcAT-P involved in glycosaminoglycan and HNK-1 carbohydrate epitope biosynthesis, respectively. Glycobiology, 17, 857-867. http://dx.doi.org/10.1093/glycob/cwm055

[66] Zhang, Y., Deshpande, A., Xie, Z.H., Natesh, R., Acharya, K.R. and Brew, K. (2004) Roles of active site tryptophans in substrate binding and catalysis by $\alpha-1,3$ galactosyltransferase. Glycobiology, 14, 1295-1302. http://dx.doi.org/10.1093/glycob/cwh119

[67] Mulders, K.J.M. and Beeftink, H.H. (2013) Chain length distribution and kinetic characteristics of an enzymaticcally produced polymer. e-Polymers, 24, 1-12. 


\section{ABBREVIATIONS}

$\alpha 3 \mathrm{GT}: \alpha 1,3$-galactosyltransferase;

$\beta 4 \mathrm{GAIT1}$ : $\beta 1$,4-galactosyltransferase;

EXTL2: $\alpha 1,4-\mathrm{N}$-acetylhexosaminlytransferase;

GlcAT1: $\beta 1,3$-glucuronosyltransferase;

GlcAT-P: $\beta 1,3$-glucuronosyltransferase;

GlcNAc: $N$-acetylglucosamine;

GlcUA: glucuronic acid;

HA: hyaluronan;

$\mathrm{HA}_{4}$ : hyaluronantetrasaccharide;

hGTA: blood group A

$\alpha 1,3-\mathrm{N}$-galactosaminyltransferase;

hT2: UDP-GalNAc:polypeptide

$\alpha$-N-acetylgalactosaminyltranserase $\mathrm{T} 2$;

K4CP: K4CP chondroitin polymerase;

LDH: lactate dehydrogenase;

LgtC: $\alpha 1$,4-galactosyltransferase;

MALDI-TOF MS: Matrix-Assisted Laser Desorption/

Ionization Time of Flight Mass Spectrometry;

NAc-transferase domain: domain in PmHAS that elongates UDP-GlcNAc to the oligosaccharide;

PmHAS: Pasteurella multocida hyaluronan synthase;

PK: pyruvate kinase;

SeHAS: Streptococcus equisimilishyaluronan synthase;

UA-transferase domain: domain in PmHAS that elongates UDP-GlcUA to the oligosaccharide;

XIHAS: Xenopuslaevis hyaluronan synthase. 